UNIVERSIDADE DE SÃO PAULO

FACULDADE DE ODONTOLOGIA DE RIBEIRÃO PRETO

GUSTAVO CAVALCANTI DE ALBUQUERQUE

\begin{abstract}
AVALIAÇÕES HISTOLÓGICA E HISTOMORFOMÉTRICA DE IMPLANTES OSSEOINTEGRÁVEIS DE TITÂNIO COM SUPERFÍCIE ANODIZADA E REVESTIDA POR Ca E P.
\end{abstract}




\section{AVALIAÇÕES HISTOLÓGICA E HISTOMORFOMÉTRICA DE IMPLANTES OSSEOINTEGRÁVEIS DE TITÂNIO COM SUPERFÍCIE ANODIZADA E REVESTIDA POR Ca E P.}

Dissertação apresentada à Faculdade de Odontologia de Ribeirão Preto da Universidade de São Paulo para a obtenção do título de Mestre em Odontologia.

Área de concentração: Cirurgia e Traumatologia Buco-Maxilo-Facial Orientador Adalberto Luiz Rosa 
Autorizo a reprodução total ou parcial deste trabalho, por qualquer meio convencional ou eletrônico, para fins de estudo e pesquisa, desde que citada à fonte.

\section{FICHA CATALOGRÁFICA}

Albuquerque, Gustavo Cavalcanti de

Avaliações histológica e histomorfométrica de implantes osseointegráveis de titânio com superfície anodizada e revestida por Ca e P. Ribeirão Preto, 2010.

40 p.: il.; $30 \mathrm{~cm}$

Dissertação de Mestrado apresentada à faculdade de Odontologia de Ribeirão Preto/USP - Area de concentração: Cirurgia e Traumatologia Buco Maxilo - Facial.

Orientador: Rosa, Adalberto Luiz.

1. Titânio. 2. Tratamento de superfície. 3. Osseointegração. 4. Implantes dentários. 


\section{Gustavo Cavalcanti de Albuquerque}

Avaliações histológica e histomorfométrica de implantes osseointegráveis de titânio com superfície anodizada e revestida por Ca e $\mathbf{P}$.

Dissertação apresentada à Faculdade de

Odontologia de Ribeirão Preto da Universidade de São Paulo para a obtenção do título de Mestre em Odontologia.

Área de concentração: Cirurgia e Traumatologia Buco-Maxilo-Facial

Orientador: Adalberto Luiz Rosa

Aprovado em:

Banca Examinadora

Prof. Dr.

Instituição:

Assinatura:

Prof. Dr.

Instituição:

Assinatura:

Prof. Dr.

Instituição: Assinatura: 


\title{
DEDICATÓRIA
}

\begin{abstract}
À Deus
Pelo dom da vida e por todas as oportunidades concedidas

Por sempre colocar no meu caminho pessoas boas

Por me dar saúde e coragem para atravessar momentos difíceis

Pela capacidade de conquistar sonhos

Pela proteção e orientação, sinto a presença dele ao meu lado em todos os momentos da minha vida!
\end{abstract}

\begin{abstract}
A minha mae, Isabel
Mãe, você foi à pessoa que mais queria ver a minha vitória Você se sacrificou para nos dar estudo e ter um futuro melhor

Você que me chamava de "meu doutorzinho" está presente e ao mesmo tempo não Por que sua consciência não esta aqui para compartilhar as minhas conquistas e ver que valeu a pena todo o esforço e dificuldade que passamos? Por todo amor eu serei eternamente grato!

\section{Ao meu pai, Fernado}

Amigo e companheiro Fez o possível e o impossível para nos dar conhecimento e alcançar nossos objetivos Você esteve sempre pronto para me socorrer quando precisei Obrigado por tudo
\end{abstract}

\section{À minha esposa, Tatiana}

Minha amiga e companheira, obrigado pela compreensão nos momentos de ausência e noites em claro, obrigado pelo apoio e incentivo, por sempre acreditar em min e estar ao meu lado nos momentos difíceis

Só Eu, Você e Deus sabem das dificuldades que enfrentei para conquistar meus sonhos e chegar aonde cheguei Te amo mais que tudo! 


\title{
AGRADECIMENTOS ESPECIAIS
}

\begin{abstract}
Aos mestres
Ao Prof. Dr. Adalberto Luiz Rosa por ter me acolhido como orientado. Uma pessoa genial que desde a primeira vez que eu o conheci passei a admirá-lo. Pela tranqüilidade proporcionada pelo seu jeito e pela extrema competência como professor e pesquisador. Sou muito orgulhoso de tê-lo como orientador.
\end{abstract}

Ao prof. Dr. Luis Eduardo Marques Padovam, o que falar de você meu amigo! Um exemplo de profissional e pessoa, um excelente pai de família, que me acolheu como se fosse um filho, acreditando no meu caráter e potencial. Você me inspira em tudo que faz, agradeço todos os dias a Deus por ter ti colocado no meu caminho. Obrigado pelos incentivos e conselhos, estarei sempre pronto quando precisar e nunca vou te decepcionar.

Ao Prof. Dr. Paulo Domingos Ribeiro Júnior, profissional de extrema competência, pessoa única, te admiro pela insaciável busca de conhecimento e pela precisão que tem em seus procedimentos. Nas situações profissionais mais difíceis lembro-me da tranquiilidade que você tem para enfrentar e solucionar. Obrigado por me ensinar e me dar à oportunidade de trabalhar ao seu lado.

Aos meus professores, Dr. Hugo Nary Filho, Eduardo Gonçales, Aparicio Dekon, Mariza Matsumoto e Roberto Kawakami responsáveis pela minha formação em cirurgia.

Aos professores de pós-graduação do Departamento de Cirurgia e Traumatologia BucoMaxilo-Facial da Faculdade de Odontologia de Ribeirão Preto (USP), pelos ensinamentos que fizeram com que eu evoluísse como professor, como pessoa e profissional.

Ao pós-doutorando Alexandrer Sverzut pela contribuição e ajuda para desenvolvimento do trabalho. Pelo respeito, compreensão e amizade. 


\section{Aos familiares e amigos}

Aos meus irmaõs, Fabiano, Fernando e Melina, por todo amor, respeito e confiança em mim depositados. Por sempre me apoiarem e acreditarem na minha capacidade e nos meus sonhos. Pelos momentos de angustia que passamos juntos e pela nossa união que foi a base para amenizar nosso sofrimento e que nos deu força para se reestruturar e continuarmos a luta.

A minha avó, tias e tios, primas e primos, cunhadas, sogro e sogra pelos momentos de felicidade e tristeza compartilhados, pelo apoio, e pela sempre presente torcida.

Aos amigos e irmãos Patrício, Marcão e William por terem me acolhido quando precisei. Realmente formamos uma família e passamos momentos inesquecíveis juntos. 


\section{AGRADECIMENTOS}

À Faculdade de Odontologia de Ribeirão Preto da Universidade de São Paulo pela acolhida durante o curso de pós-graduação.

À Fapesp, pelo auxilio financeiro ao projeto e pela bolsa concedida.

À todos os funcionários dos Departamento de Cirurgia e Traumatologia Buco-MaxiloFacial e Periodontia, do Laboratório de Microscopia, Laboratório de Histologia e do Biotério de cães, pela amizade e ajuda imprescindíveis: Tatiana, Dulce, Adriana, Sebastião, Júnia, Aldo, "Marmita" e Fábio.

Aos colegas do curso de Mestrado que proporcionaram um ambiente de estudo agradável, pela convivência nos momentos de apreensão e momentos de alegria, vivemos momentos inesquecíveis: Ana Carolina Hawthorne, Luciana Scchieri, Marcelo Rodrigues Azenha, Michel Campos Ribeiro, Patrício de Oliveira Neto, Renan Bueno, Rogério Bentes kato. 


\section{RESUMO}

ALBUQUERQUE, GC. Avaliação histológica e histomorfométrica de implantes osseointegráveis de titânio com superfície anodizada e revestida por Ca e P. 2010. 40 p. Dissertação (Mestrado) - Faculdade de Odontologia de Ribeirão Preto, Universidade de São Paulo, Ribeirão Preto, 2010.

Estudos de modificações de superfície de implantes de Ti têm atraído a atenção dos pesquisadores por existir grande interesse em tratamentos que possam acelerar o processo fisiológico de reparo do tecido ósseo em contato com o Ti. Avaliações in vitro mostraram que superfícies de Ti obtidas por modificação físicoquímica como a anodização (anodic spark discharge - ASD) podem representar uma boa alternativa para melhorar a osseointegração de implantes. O objetivo deste estudo foi avaliar a resposta do tecido ósseo de mandíbula de cães a implantes osseointegráveis de Ti com superfície modificada por duplo ataque ácido (AE), por anodização em solução de íons cálcio e fosfato (ASD-AK) e anodização em solução de silício, cálcio e fosfato seguido por ataque alcalino em $\mathrm{NaOH}$ (SiB-Na). Para isso dez cães foram submetidos a exodontia dos pré-molares 12 semanas antes das instalação dos implantes. Os animais foram sacrificados no período de 5 e 8 semanas (cinco por período) e os segmentos ósseos contendo os implantes foram processados. Foram avaliados os efeitos dos tratamentos de superfície na (1) porcentagem de contato direto osso-implante, (2) formação óssea entre as roscas do implante e (3) formação óssea à distância da superfície do implante. Os resultados mostraram que todos os tratamentos (AE, ASD-AK e SiB-Na) permitiram formação óssea em contato direto e adjacente à superfície de Ti sem apresentar nenhum diferença qualitativa e quantitativa no padrão de reparo ósseo. Portanto, esses tratamentos deveriam ser avaliados clinicamente na reabilitação implanto-suportada de pacientes parcial ou totalmente edêntulos.

Palavras-chave: Titânio. Tratamento de superfície. Osseointegração. Implantes dentários. 


\begin{abstract}
ALBUQUERQUE, GC. Histological and Histomorphometric analysis of Ti implants with surfaces modified by anodic spark deposition in Ca and P. 2010. 40 p.

Dissertação (Mestrado) - Faculdade de Odontologia de Ribeirão Preto, Universidade de São Paulo, Ribeirão Preto, 2010.
\end{abstract}

Surface modification of $\mathrm{Ti}$ have been attracted the attention of the researchers for existing great interest in treatments that can speed up the physiological process of repair of the bone contact. Aiming to improve the osseointegration of Ti implants several surface treatments have been proposed including those obtained by anodic spark deposition technique (anodic spark discharge - ASD). This treatment allows to developing a thin and porous surface layer enriched with selected ions from the electrochemical solution. This study was designed to analyze bone repair adjacent to and in contact with Ti implants with surfaces modified by acid etching (AE) and anodic spark deposition (ASD). Surface modification of Ti implants was carried out by three methods: AE, ASD in calcium and phosphate solution (ASD-AK), and ASD in calcium, phosphate and silicon solution followed by alkali etching in $\mathrm{NaOH}$ ( $\mathrm{SiB}-\mathrm{Na}$ ). Ten mongrel dogs were submitted to premolar extraction and after 12 weeks AE, BS, and $\mathrm{SiB}-\mathrm{Na}$ self-screw Ti implants were placed into edentulous areas. Animals were killed at 3 and 8 weeks (five per period) and bone fragments with implants harvested and processed to obtain thin ground sections. Histomorphometric analysis was carried out to determine the bone-implant contact (BIC), bone area between threads (BABT), and bone area adjacent to threads (BAAT). The results had shown that all the treatments (AE, ASD-AK and SiB-Na) had allowed bone formation in direct and adjacent contact to the surface, without qualitative and quantitative difference in the standard of bone repair. Therefore, these surface treatments would have clinically to be evaluated in the implant-supported rehabilitation of total edentulous or patients partial.

key- word: Titanium. Surface treatment. Osseointegration. Dental implants. 


\section{LISTA DE ABREVIATURAS}

- AE: duplo ataque ácido

- ASD (anodic spark discharge): deposição anódica por faísca

- ASD-AK: anodização em solução de íons cálcio e fosfato

- BIC (bone-implant contact): porcentagem de contato direto osso-implante

- BABT (bone area between threads): formação óssea entre as roscas do implante

- BAAT (bone area adjacent to threads): formação óssea à distância da superfície do implante

- Ca: Cálcio

- DEF: Deposição Eletroforética

- HA: hidroxiapatita

- KOH: hidróxido de potássio

- NaOH: hidróxido de sódio

- $\quad$ p: nível de significância

- P: fosfato

- RNAm: (rubonucleic acid): ácido ribonucléico mensageiro

- SiB-Na: anodização em solução de silício, cálcio e fosfato seguido por ataque alcalino em $\mathrm{NaOH}$

- Si: silicio

- Ti: titânio 


\section{SUMÁRIO}

RESUMO

ABSTRACT

LISTA DE ABREVIATURAS

1. INTRODUÇÃO

2. OBJETIVOS

3. MATERIAIS E MÉTODOS

3.1. IMPLANTES

3.2. PROCEDIMENTO CIRÚRGICO

3.3. PROSESSAMENTO HISTOLÓGICO

3.3.1. DESIDRATAÇÃO E INFILTRAÇÃO DAS PEÇAS

3.3.2. INCLUSÃO/POLIMERIZAÇÃO DAS PEÇAS

3.3.3. CORTE E DESGASTE DAS PEÇAS

3.4. ANÁLISE HISTOLÓGICA

3.5. ANÁLISE HISTOMORFOMÉTRICA 24

3.6. ANÁLISE ESTATÍSTICA 24

4. RESULTADOS 26

4.1. AVALIAÇÃO CLÍNICA 26

4.2. ANÁLISE HISTOLÓGICA 26

4.3. ANÁLISE HISTOMORFOMÉTRICA 29

5. DISCUSSÃO 32

6. CONCLUSÃO 35

7. REFERÊNCIAS BIBLIOGRÁFICAS 36 


\section{INTRODUÇÃO}

$\mathrm{Na}$ área da Implantodontia um dos fenômenos mais intensamente investigado é a osseointegração de implantes, o objetivo sendo sempre o de acelerar e/ou incrementar esse processo, visando uma reabilitação rápida e eficiente de pacientes edentados. Muitos estudos sugerem que a topografia e a composição da superfície dos implantes de titânio (Ti) parecem ser importantes no que diz respeito aos resultados clínicos (Ferguson e cols., 2008; Cochran, 1999). O Ti é o biomaterial mais freqüentemente usado para a fabricação de implantes, por apresentar excelente biocompatibilidade. Está bem estabelecido que a proporção de contato direto ossobiomaterial é influenciada por características do implante, como o material empregado, a morfologia e a composição química, e por parâmetros clínicos, como condições do leito hospedeiro, técnica cirúrgica e utilização de carga (Albrektsson e Johansson, 1991).

A despeito do titânio comercialmente puro (cpTi) em sua forma nativa proporcionar somente união mecânica, modificações químicas podem torná-lo um material bioativo (Albrektsson e Wennerberg, 2004). Assim sendo, o estudo de modificações de superfície de Ti é uma área de pesquisa bastante ativa por existir grande interesse em tratamentos que possam acelerar o processo fisiológico de reparo do tecido ósseo em contato com o Ti (Morra e cols., 2003). Puleo e Nanci (1999) em uma revisão acerca da interface osso-implante descreveram três possíveis abordagens para a modificação de superfície de Ti, sendo: (1) métodos morfológicos, (2) métodos bioquímicos e (3) métodos físico-químicos.

Os métodos morfológicos, baseados no jateamento com $\mathrm{A} 12 \mathrm{O} 3$ ou TiO2 e/ou no ataque ácido com $\mathrm{HNO} 3, \mathrm{HCl}, \mathrm{H} 2 \mathrm{SO}$, são os mais comumente utilizados para promover modificações de superfície de Ti e também os mais abordados pela literatura (Wall e cols., 2009; Tavares e cols., 2007; Rosa e Beloti, 2003a; Xavier e cols., 2003; 
Wennerberg e cols., 1998; Martin e cols., 1995). Estudos in vitro mostraram que a rugosidade de superfície altera a adesão, a proliferação e a diferenciação osteoblástica e a produção de matriz extracelular (Wall e cols., 2009; Rosa e Beloti, 2003b; Kieswetter e cols., 1996). Além disso, alguns estudos indicam que a rugosidade de superfície afeta a produção de citocinas, fatores de crescimento e RNA mensageiro, sugerindo que a rugosidade de superfície modula a atividade das células adjacentes ao biomaterial e, conseqüentemente, influencia a falha ou o sucesso do implante (Schwartz e cols., 1997; Kieswetter e cols., 1996). Wall e cols. (2009) demonstraram que a diferenciação osteogênica das células mesenquinais do estroma humano em superfícies de Ti modificadas, foi favorável por induzir mais rapidamente a mineralização da matriz óssea.

Energia, carga e composição de superfície estão entre as características físicoquímicas que podem ser alteradas com o objetivo de melhorar a osseointegração do Ti. Tratamentos para revestir superfícies de Ti com hidroxiapatita (HA) ou cálciofosfato $(\mathrm{Ca}-\mathrm{P})$ também têm sido extensivamente investigados por se tratar de materiais quimicamente semelhantes à porção mineral do tecido ósseo (Jarcho, 1981). O principal objetivo do revestimento de superfícies de Ti com HA ou Ca-P é acelerar a formação de tecido ósseo em íntimo contato com o implante, por ocorrer uma interação química entre osso e HA ou Ca-P (Fini e cols., 1999). Várias técnicas, como jateamento, deposição por laser, deposição por irradiação, pressão isostática, deposição eletroforética, sol-gel e implantação de íons, podem ser empregadas para revestir o Ti com um filme de HA ou de Ca-P (Satsangi e cols., 2003).

Stadlinger e cols. (2009) destacaram que a utilização de íons de Hidróxido aumentaria a energia superficial e capacidade de molhamento da superfície do implante estimulando a interação entre esta e o ambiente biológico. Em seu estudo na qual 
utilizou-se superfícies híbridas (jateamento de areia + ataque ácido) associado com imersão na solução de íons de Hidróxido antes da implantação cirúrgica, verificou que apesar dos resultados não atingirem significância estatística, houve uma tendência do processo de osseointegração ocorrer em períodos mais curtos.

Segundo Barros e cols., (2009) a interação osso-implante é complexa e não depende única e exclusivamente da topografia do implante. Composições químicas e bioquímicas da superfície desenvolvem um papel importante na fase primária da formação óssea. Em seu trabalho, investigou se superfícies biofuncionalizadas com peptídeos bioativos influenciavam o contato osso-implante e a densidade do osso ao redor dos implantes. Concluíram que, a biofuncionalização da superfície de implantes pode interferir na aposição óssea, em particular na densidade óssea, e que diferentes concentrações peptídicas podem conduzir a diferentes resultados.

Entre os diferentes métodos, o mais utilizado para o revestimento de superfície de Ti, é o jateamento com HA (Satsangi e cols., 2003). Tal tratamento melhora a osseointegração, especialmente em avaliações de curto período, impedindo a formação de tecido fibroso na interface osso-implante (Tisel e cols., 1994). No entanto, falhas na performance de implantes de $\mathrm{Ti}$, revestidos com $\mathrm{HA}$ ou $\mathrm{Ca}-\mathrm{P}$, avaliada em longos períodos foram relatadas e relacionadas com problemas de adesão entre o filme de HA ou Ca-P e o substrato, não uniformidade na deposição, resultando em diferentes espessuras do revestimento de HA, microfraturas e dissolução não controlada do revestimento (Kokubo e cols., 1996; Filiaggi e cols., 1991). Além disso, em razão do processamento envolvido na confecção destes revestimentos, a superfície de HA ou Ca$\mathrm{P}$ apresenta-se altamente texturizada, podendo também ocorrer uma transformação química, causada pelas altas temperaturas utilizadas no processamento, com a formação de outros produtos de composição e cristalinidade diferentes da HA utilizada como 
substituto ósseo (Rosa e cols., 2000). Tais problemas, contudo, não refletem falhas inerentes ao filme de $\mathrm{HA}$ ou $\mathrm{Ca}-\mathrm{P}$, mas limitações das técnicas utilizadas para a deposição do revestimento (Satsangi e cols., 2003).

Em razão dos problemas enumerados acima, novas pesquisas sobre métodos alternativos para o revestimento de superfície do Ti com HA ou Ca-P estão sendo realizadas. Um tratamento de superfície que vem sendo muito estudada é a Deposição Eletroforética (DEF) de HA, que representa um processo tecnológico importante devido a sua simplicidade e baixo custo. As vantagens incluem a habilidade de revestir com a espessura uniforme, grande escala de porosidade, capacidade de revestir formas complexas, e a facilidade do controle da composição química. Estes revestimentos têm uma forte adesão ao substrato e são compostos principalmente de fases puras sem nenhuma fase metaestável ou misturadas (Kim \& Ramaswamy, 2009). Outra técnica que pode ser aplicada para a obtenção de um revestimento enriquecido com $\mathrm{Ca}-\mathrm{P}$ é conhecida como anodic spark discharge (ASD) (Kryssman e cols., 1984). Revestimentos obtidos por esse processo apresentam boas propriedades mecânicas e químicas, assim como porosidade controlada em escala micrométrica (Sandrini e cols., 2003). O filme, obtido por esse método, se adere ao substrato e sua estequiometria pode ser controlada de forma a se obter uma proporção precisa entre as quantidades de Ca e P (Kurze, 1995; Kim \& Ramaswamy, 2009).

Zhu e cols., (2001) e Ishizawa e Ogino (1995) desenvolveram dois métodos similares para o revestimento de superfície do Ti com Ca-P baseados na técnica ASD, utilizando soluções ricas em $\mathrm{Ca}$ e $\mathrm{P}$. O revestimento obtido por tais tratamentos é constituído por um filme de aproximadamente $5 \mu \mathrm{m}$ de $\mathrm{TiO} 2$ enriquecido com $\mathrm{Ca}$ e $\mathrm{P}$. Além disso, Ishizawa e Ogino (1995) adicionaram ao método de revestimento por ASD um tratamento hidrotérmico com a finalidade de transformar áreas amorfas do 
revestimento em HA. No entanto, o tratamento hidrotérmico favoreceu a formação de núcleos de HA fracamente aderidos à superfície do substrato, prejudicando as respostas teciduais ao implante (Fini e cols., 1999).

Sandrini e cols. (2003) propuseram uma mudança na técnica de revestimento por ASD, acrescentando ao método original um tratamento alcalino com KOH (ASDAK). Foi observado que superfícies submetidas a esse processamento, e não ao tratamento hidrotérmico proposto por Ishizawa e Ogino (1995), apresentam uma camada homogênea de $\mathrm{Ca}$ e $\mathrm{P}$ em contato direto com o Ti, além de um grande potencial para permitir o depósito de nódulos de mineralização (Sandrini e cols., 2003). Estudos realizados por nosso grupo mostraram que a superfície ASD-AK, quando comparada à superfície usinada, favorece eventos intermediários da osteogênese in vitro e proporciona maior contato osso-implante em cilindros implantados em úmeros de cães (Franco e cols., 2006 e 2008). Ravanetti e cols. (2010) confirmaram os resultados biológicos favoráveis in vitro e in vivo.

No entanto, o grupo do Professor Roberto Chiesa do Institute Politecnico di Milano (Itália) apresentou uma nova modificação do método ASD, que consiste em realizar o procedimento em soluções com silício, cálcio e fosfato seguido por ataque alcalino em $\mathrm{NaOH}(\mathrm{SiB}-\mathrm{Na})$. Esse tratamento resulta em superfícies com morfologia microporosa enriquecidas com $\mathrm{Si}, \mathrm{Ca}, \mathrm{P}$ e $\mathrm{Na}$ com potencial para mineralização e altamente hidrofílicas (Della Valle et al., 2009). No entanto, a resposta do tecido ósseo a implantes de Ti com superfícies modificadas por esse método ainda não foi avaliada. 


\section{OBJETIVOS}

\section{Objetivo geral}

Avaliar a resposta do tecido ósseo de mandíbula de cães a implantes osseointegráveis de Ti com superfície modificada por duplo ataque ácido com ácido sulfúrico (AE), por anodização em solução de íons $\mathrm{Ca}$ e $\mathrm{PO}_{4}(\mathrm{ASD}-\mathrm{AK})$ e anodização em solução com íons de $\mathrm{Ca}, \mathrm{PO}_{4}$ e $\mathrm{Si}$ seguida de ataque alcalino com $\mathrm{NaOH}$ ( $\mathrm{SiB}-\mathrm{Na}$ ).

\section{Objetivos específicos}

Avaliar o efeito dos tratamentos de superfície:

1. formação óssea em contato direto com a superfície dos implantes (BIC do inglês bone-to-implant contact).

2. formação óssea entre as roscas do implante (BABT do inglês bone area between threads).

3. formação óssea à distância da superfície dos implantes (BAAT do inglês bone area adjcent to threads). 


\section{MATERIAL E MÉTODOS}

\subsection{IMPLANTES}

Foram utilizados implantes auto-rosqueáveis de Ti de 3,75 mm de diâmetro e 8,5 mm de comprimento (BioImplant, Itália) com superfícies modificadas pelo Prof. Roberto Chiesa do Institute Politecnico di Milano (Itália) utilizando os métodos descritos por Sandrini e cols. (2003) e Della Valle e cols. (2009). Os diferentes tratamentos de superfícies são mostrados na tabela 1 e os implantes utilizados, na figura1.

Tabela 1- Tratamentos de superfícies de implantes osseointegráveis de Ti.

TRATAMENTOS DE SUPERFÍCIE

AE Duplo ataque ácido com ácido fluorídrico e mistura de ácido sulfúrico e fosfórico

ASD-AK Anodização em solução de íons $\mathrm{Ca}$ e $\mathrm{PO} 4$

$\mathrm{SiB}-\mathrm{Na} \quad$ Anodização em solução de íons $\mathrm{Ca}, \mathrm{PO} 4$ e Si seguida de ataque alcalino com $\mathrm{NaOH}$

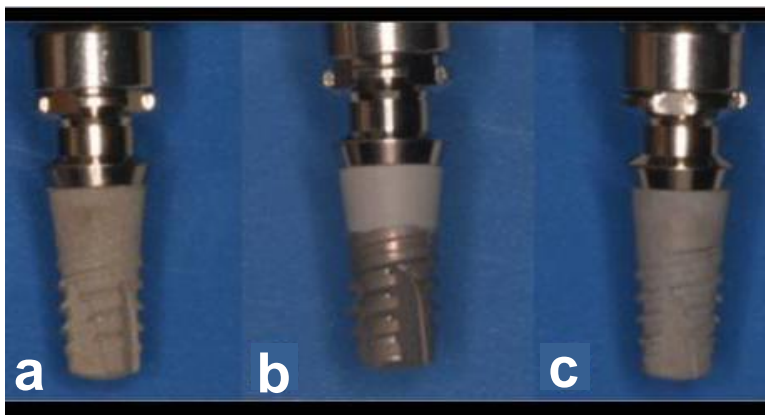

Figura 1 - Implantes osseointegráveis de Ti com diferentes tratamentos de superfície. (a) Superfície modificada por duplo ataque ácido (AE). (b) Superfície modificada por anodização em solução de íons $\mathrm{Ca}^{2} \mathrm{PO}_{4}$ (ASD-AK). (c) Superfície modificada pelo método de anodização em solução com íons de $\mathrm{Ca}, \mathrm{PO}_{4}$ e $\mathrm{Si}$ seguida de ataque alcalino com $\mathrm{NaOH}(\mathrm{SiB}-\mathrm{Na})$. 


\subsection{PROCEDIMENTOS CIRÚRGICOS}

Dez cães adultos jovens, de raça não definida, pesando entre $20 \mathrm{e} 31 \mathrm{~kg}$ foram utilizados no presente estudo. Os animais foram anestesiados através de injeção intramuscular de pré-anestésico Rompun 2\% - $20 \mathrm{mg} / \mathrm{kg}$ (Bayer, Alemanha) na dosagem de $0,05 \mathrm{ml} / \mathrm{kg}$ e depois de sedados, receberam injeção intravenosa de tiopental (Cristália, SP, Brasil) $1 \mathrm{ml} / \mathrm{kg}$ (solução de $20 \mathrm{mg} / \mathrm{kg}$ diluídos em $50 \mathrm{ml}$ de soro fisiológico). A anti-sepsia extra - oral foi realizada com solução de iodo degermante e intra oral com solução de iodo tópico. Após infiltração com anestésico local, um retalho total envolvendo os premolares foi realizado em ambos os lados da mandíbula. Os dentes premolares foram seccionados para que as raízes pudessem ser individualmente extraídas sem danificar as paredes ósseas e, após as extrações, alveoloplastia, gengivoplastia, curetagem e irrigação foram realizadas e os retalhos foram reposicionados e suturados com fios absorvíveis de poligalactina 910 4-0 (Vicryl, Ethicon, SP, Brasil).

Ao final de doze semanas, os cães foram anestesiados novamente e submetidos a novo procedimento cirúrgico para colocação bilateral dos implantes, seguindo o protocolo de fresagens proposto pelo fabricante para posterior instalação dos implantes (Figura 2. a-b e Figura 3).
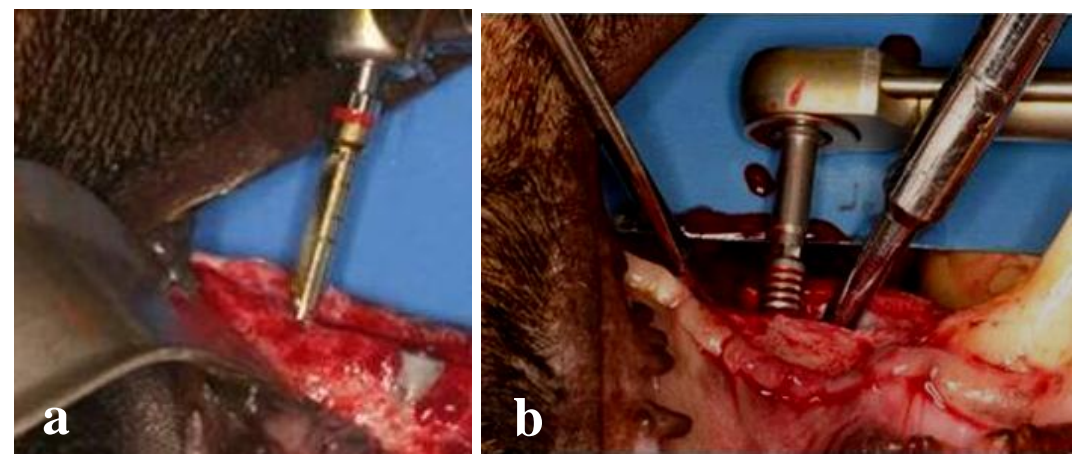

Figura 2. (a- b) Procedimento cirúrgico para instalação dos implantes. 


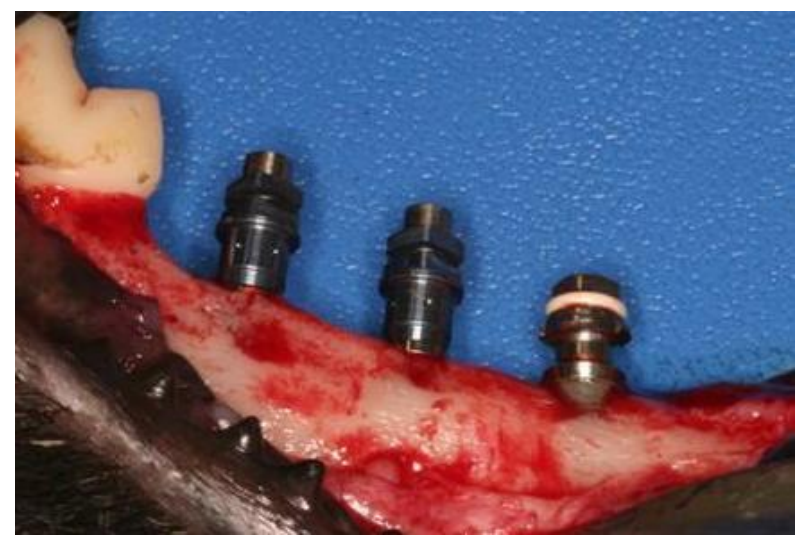

Figura 3. Implantes instalados na mandíbula após seqüência de fresagem.

Os implantes foram distribuídos de forma aleatória entre os animais de modo que doze implantes para cada tratamento de superfície pudessem ser avaliados (Figura $4)$.

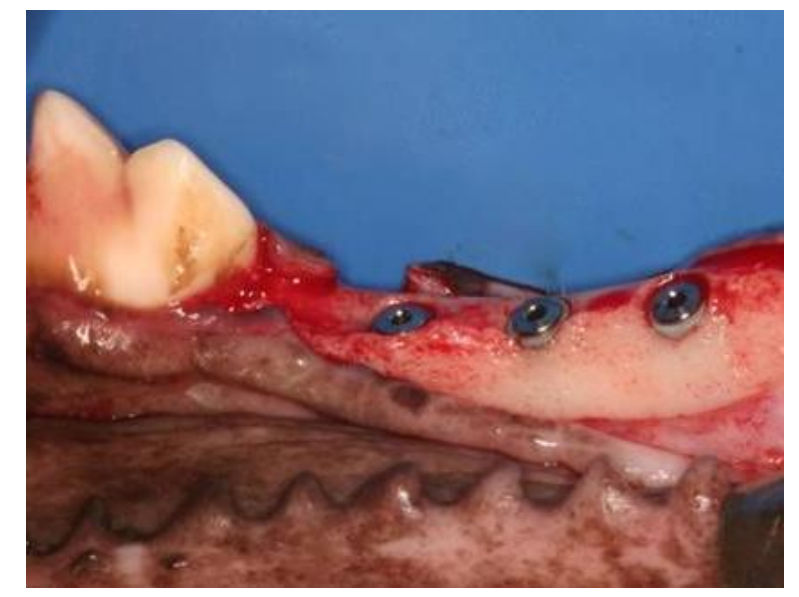

Figura 4. Implantes instalados na mandíbula.

Após três e oito semanas da implantação, os animais foram mortos por dose excessiva de pentobarbital e os segmentos ósseos contendo os implantes foram reduzidos através de osteotomia realizada com discos de diamante (KG Sorensen, SP, Brasil), sob irrigação abundante com solução de cloreto de sódio a $0,9 \%$, deixando-se uma margem de aproximadamente $5 \mathrm{~mm}$ de distância de cada lado da área do implante (Figura 5). 


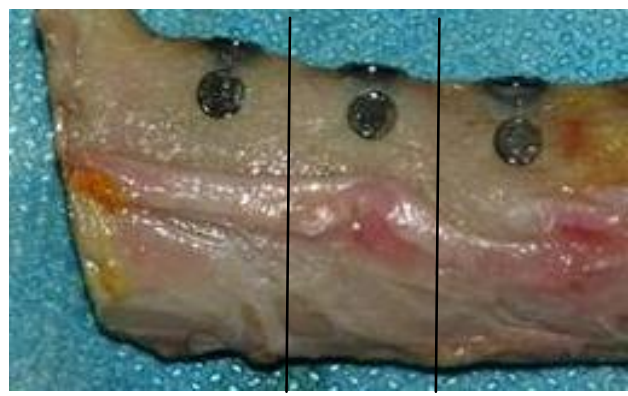

Figura 5. Segmentos ósseos contendo os implantes separados com discos diamantados.

\subsection{PROCESSAMENTO HISTOLÓGICO}

\subsubsection{Desidratação e infiltração das peças}

Cada uma das peças foi fixada em solução de formalina a $10 \%$ com pH 7 por 10 dias, a qual foi trocada a cada 2 dias. Decorrido este prazo as peças foram transferidas para uma solução de etanol a $70 \%$ vv até seu processamento.

Após fixação e lavagem, os espécimes foram desidratados em álcool etílico sob constante agitação. Terminada a desidratação as amostras foram acondicionadas em recipientes de polietileno contendo resina pura (LR White Hard Grade, London, UK) e mantidas sob agitação por 60 minutos (Tabela 2). Posteriormente, os espécimes foram armazenados e mantidos por 12 a 18 horas em refrigerador a $4^{\circ} \mathrm{C}$. Decorrido este prazo, as peças foram mantidas no vácuo por uma hora agitadas por igual tempo e novamente armazenadas em refrigerador a $4^{\circ} \mathrm{C}$ por 24 horas.

Esta rotina foi repetida por nove dias, trocando-se a resina a cada 48 horas. 
Tabela 2 - Seqüência de desidratação e infiltração em resina das peças para posterior processamento histológico.

\begin{tabular}{lc}
\hline Concentração Álcool/ $\mathbf{H}_{2} \mathbf{O}$ & Dias \\
\hline $60 \%$ & 3 \\
$80 \%$ & 3 \\
$96 \%$ & 3 \\
$100 \%$ & 3 \\
$100 \%$ & 3 \\
\hline Resina LR White & Dias \\
\hline Resina Pura & 3 \\
Resina Pura & 3 \\
Resina Pura & 3 \\
\hline
\end{tabular}

\subsubsection{Inclusão/polimerização das peças}

No décimo dia, após a troca da resina, as peças foram incluídas em moldes de teflon preparados para este fim, e devidamente identificadas foram levadas para estufa a $60^{\circ} \mathrm{C}$ por 12 a 18 horas, para que ocorresse a polimerização da resina.

O tempo de polimerização e a temperatura são fundamentais para as características físicas dos blocos. As amostras processadas dessa forma permitem uma perfeita infiltração da resina e os blocos tornam-se duros, transparentes e podem ser cortados facilmente.

\subsubsection{Corte e desgaste das peças}

Os blocos foram então removidos do molde e cortados ao meio no longo eixo do implante através do sistema Exakt (Exakt Cuttingand Grinding system, Apparatebau Gmbh, Hamburgo, Alemanha) (Figura 6). O bloco cortado ao meio foi fixado em lâmina acrílica específica do sistema Exakt e a primeira face do bloco foi polida por microdesgaste com uma seqüência de lixas P320, P800, P2500, P4000 (Hermes 
Schleifmittel GmbH \& Co., Hamburgo, Alemanha) até que a face ficasse totalmente polida sem nenhum indício de riscos.
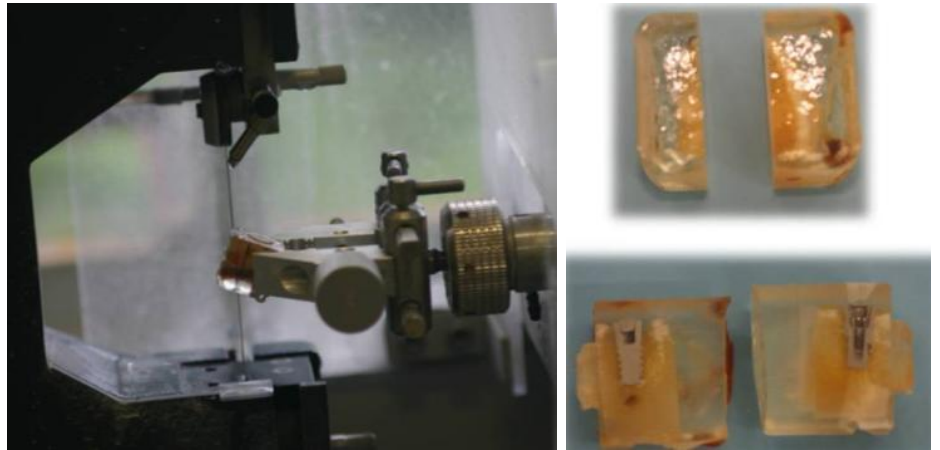

Figura 6. Corte no centro do implante utilizando serra do sistema Exakt (Exakt Cuttingand Grinding system, Apparatebau Gmbh, Hamburgo, Alemanha).

A face polida do bloco foi colada em lâmina acrílica com resina Technovit 4000 (Kulzer, Wehrheim, Alemanha) que se polimeriza por 15 minutos de incidência de luz ultravioleta (Figura7), então foi realizado um corte preliminar de aproximadamente 300 a $500 \mu \mathrm{m}$, o qual foi submetido à microdesgaste seguindo a mesma seqüência de lixas descritas anteriormente resultando em uma secção de aproximadamente 40 a $60 \mu \mathrm{m}$. Em seguida, as lâminas foram submetidas à coloração com azul de Stevenel e vermelho de Alizarina, conforme descrito por Maniatopoulos e cols. (1986).
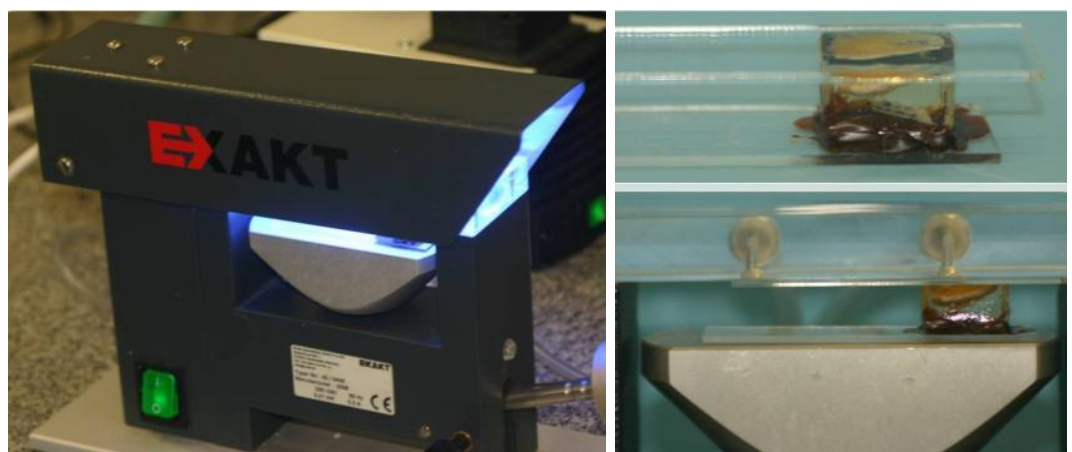

Figura 7. Polimerização da face polida na lamina a ser obtida. 


\subsection{ANÁLISE HISTOLÓGICA}

Foi feita uma análise descritiva das áreas observadas utilizando um microscópio de luz (Leica DM LB2 - Leica Microsystems Wetzlar GmbH - Nussloch, Alemanha) avaliando- se as características dos tecidos próximo aos implantes.

\subsection{ANÁLISE HISTOMORFOMÉTRICA}

A análise histomorfométrica foi realizada em imagens obtidas por microscópio de luz acoplado a uma videocâmera (Leica DC300 F) e empregando o software Leica QWin (Leica QWin - Image processing and analysis system- Leica Microsystems Wetzlar GmbH - Alemanha).

Foi avaliado o BIC, expresso como a porcentagem do perímetro medido a partir da primeira rosca cervical em direção ao ápice do implante até a quarta rosca. O BABT, expresso como a porcentagem de osso mineralizado entre quatro roscas consecutivas bilateralmente de cada implante e o BAAT, expresso como a porcentagem de osso mineralizado em uma área retangular tangenciando também quatro roscas consecutivas dos implantes bilateralmente.

Essas análises foram realizadas por um único examinador sem conhecimento prévio do tratamento de superfície dos implantes, para se evitar possíveis tendências a desvios. Para cada imagem capturada, as medidas de BIC, BABT e BAAT foi realizada três vezes e a média dessas três medidas foi considerada como o valor obtido para cada parâmetro.

\subsection{ANÁLISE ESTATÍSTICA}

Os dados foram comparados por meio do teste de Análise de Variância (ANOVA) com dois fatores de variação (modificação da superfície e tempo de implantação), seguido pelo teste de Tukey, quando apropriado, e utilizando nível de 
significância de 5\%. 


\section{RESULTADOS}

\subsection{AVALIAÇÃO CLÍNICA}

Após 3 meses das exodontias todos os animais apresentavam-se clinicamente com uma cicatrização satisfatória da região receptora dos implantes. Entretanto, em um dos animais verificou-se uma severa reabsorção da tabua óssea vestibular, situação esta, que induziu a um pobre travamento dos implantes em ambos os lados da mandíbula. Após o período de cicatrização, todos implantes apresentavam-se com perda óssea severa, relevantes sinais de inflamação e tecido fibroso adjacente a superfície caracterizando a não osseointegração, sendo assim estes implantes excluídos da análise histomorfométrica.

\subsection{ANÁLISE HISTOLÓGICA}

Para todos os implantes avaliados, observou-se a formação de tecido ósseo ao redor dos implantes e ausência de tecido fibroso.

Diferenças histológicas significativas foram observadas entre os períodos, mas não entre os diferentes tipos de implante avaliados. No período de 3 semanas foi possível identificar muitas trabéculas ósseas contendo osteócitos e revestidas por tecido osteóide e osteoblastos, indicativos do processo de formação óssea. Em algumas poucas áreas foi possível observar a presença de osteoclastos em áreas próximas àquelas de formação óssea (Figura 8). Ao final de 8 semanas, houve um aumento na quantidade de tecido ósseo mineralizado nas proximidades dos implantes, no entanto, poucas áreas de formação óssea foram observadas (Figura 9).

Aparentemente, a formação óssea se deu predominantemente por osteogênese à distância porque somente em poucas áreas foi possível observar a formação óssea ocorrendo em íntimo contato e a partir da superfície dos implantes. 

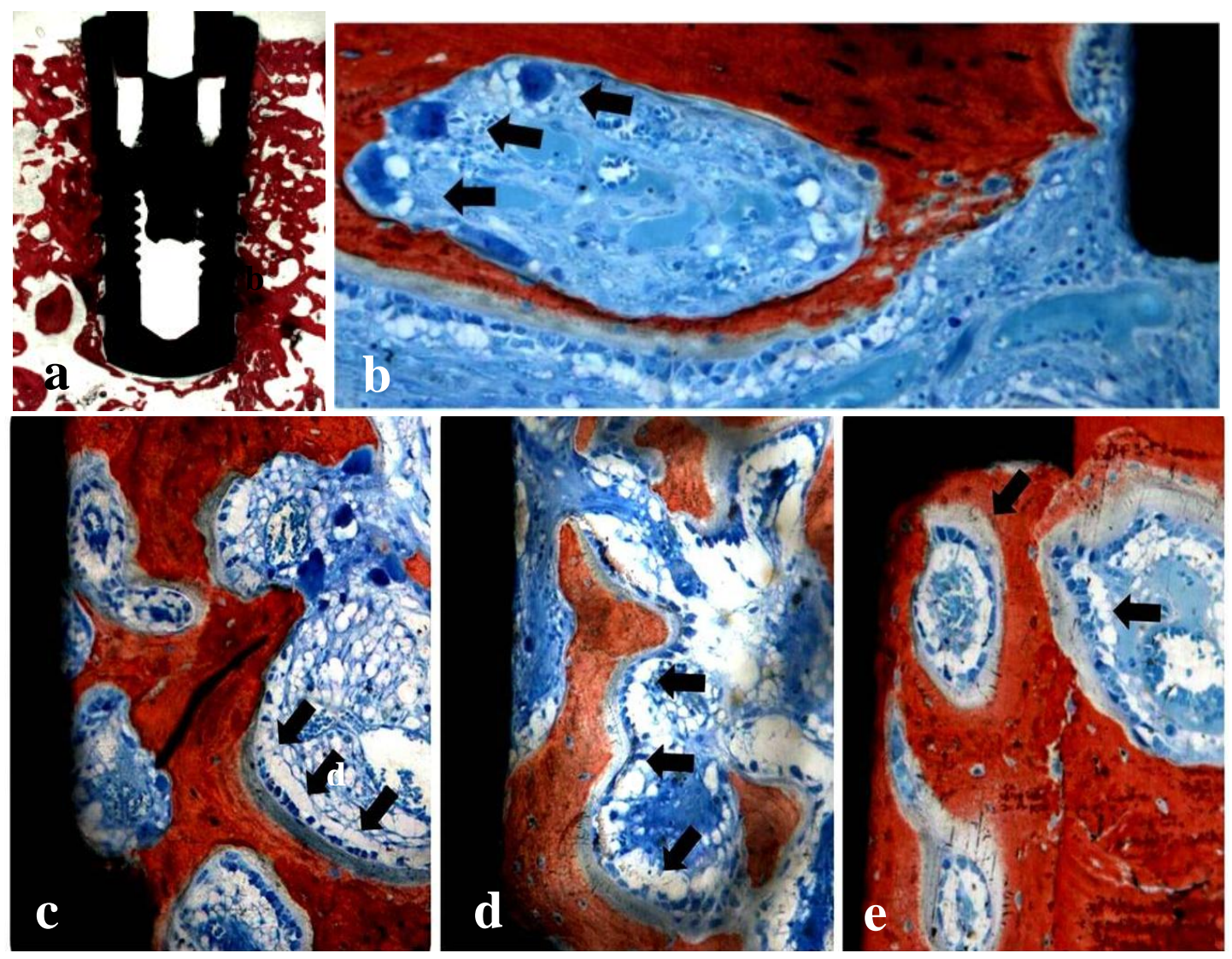

Figura 8. Fotomicrografia dos implantes após 3 semanas de implantação. a) Visão panorâmica do implante e tecido ósseo (objetiva de $0.05 \mathrm{x}$ ). b) Trabécula óssea contendo tecido osteóide revestido por osteoblastos e com osteoclastos (seta) (objetiva 20x). Setas indicando tecido osteóide sendo depositado por osteoblastos ativos em trabéculas próximas aos implantes modificados por ASD-AK (c), AE (d) e SiB-Na (e).Objetiva de 10x (c,d,e). 

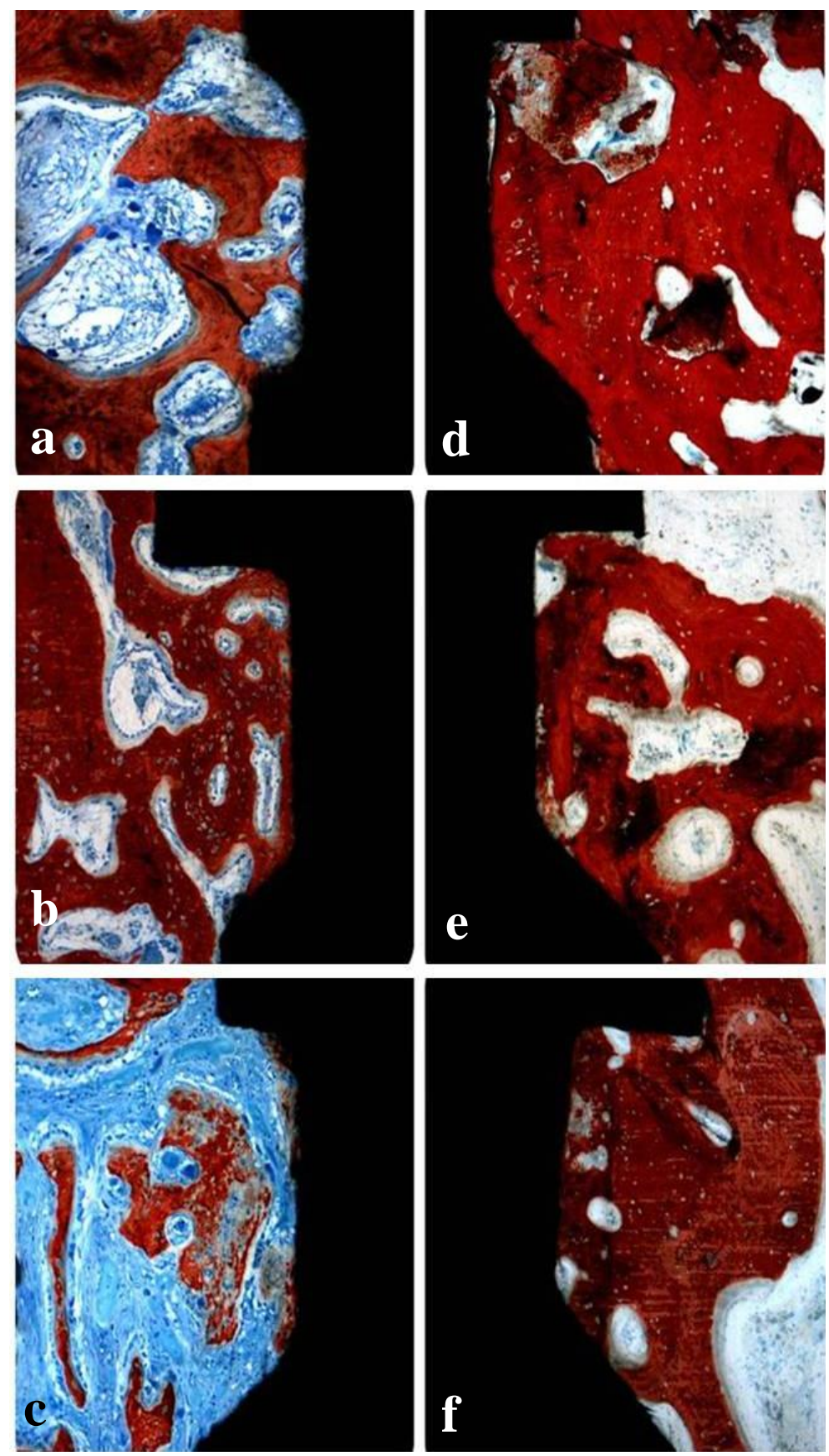

Figura 9. Fotomicrografia dos implantes após 3 (a, b, c) e 8 semanas (d, e, f) de implantação. Observar aumento na formação óssea de 3 para 8 semanas nos implantes modificados por ASD-AK ( $\mathrm{a}-\mathrm{d}$, respectivamente), $\mathrm{AE}(\mathrm{b}-\mathrm{e}$, respectivamente) e $\mathrm{SiB}-\mathrm{Na}(\mathrm{c}-\mathrm{f}$, respectivamente). Objetiva $10 \mathrm{X}$. 


\subsection{ANÁLISE HISTOMORFOMÉTRICA}

Não foram encontradas diferenças estatisticamente significantes entre os implantes de Ti relacionadas às modificações de superfície para os valores de BIC $(\mathrm{p}=0,06)$, BABT $(\mathrm{p}=0,38)$ e BAAT $(\mathrm{p}=0,38)$. No entanto, todos esse parâmetros foram afetados pelo tempo de implantação, sendo maiores após 8 semanas $(\mathrm{p} \leq 0,001)$.

Embora os valores de BIC tenham aumentado com o tempo de implantação, somente os implantes modificados por AE mostraram após 8 semanas diferença estatisticamente significante, detectada pelo teste de Tukey, em relação aos valores de BIC após 3 semanas de implantação (Figura 10).

Em relação aos valores de BABT, para todos os implantes os valores encontrados após 8 semanas de implantação foram maiores do que após 3 semanas (Figura 11).

Para os valores de BAAT, apesar de ter ocorrido aumento de 3 para 8 semanas, somente para a modificação por $\mathrm{SiB}-\mathrm{Na}$ foi detectado aumento estatisticamente significante (Figura 12). 


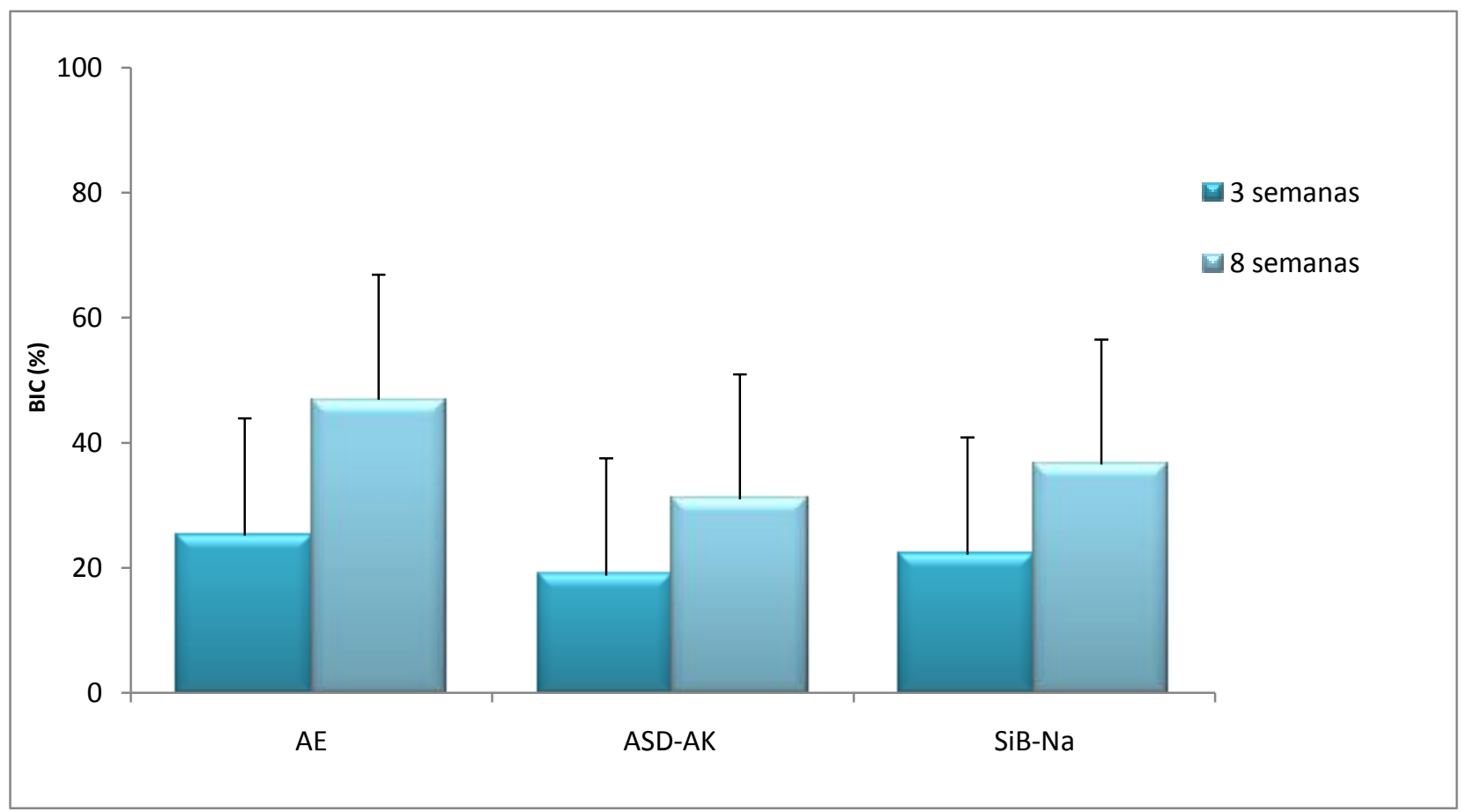

Figura 10. Formação óssea em contato direto com a superfície dos implantes (BIC) após 3 e 8 semanas de implantação para implantes com superfícies modificadas pelos tratamentos AE, ASD-AK e SiB-Na. Dados mostrados como média \pm desvio padrão $(n=6)$.

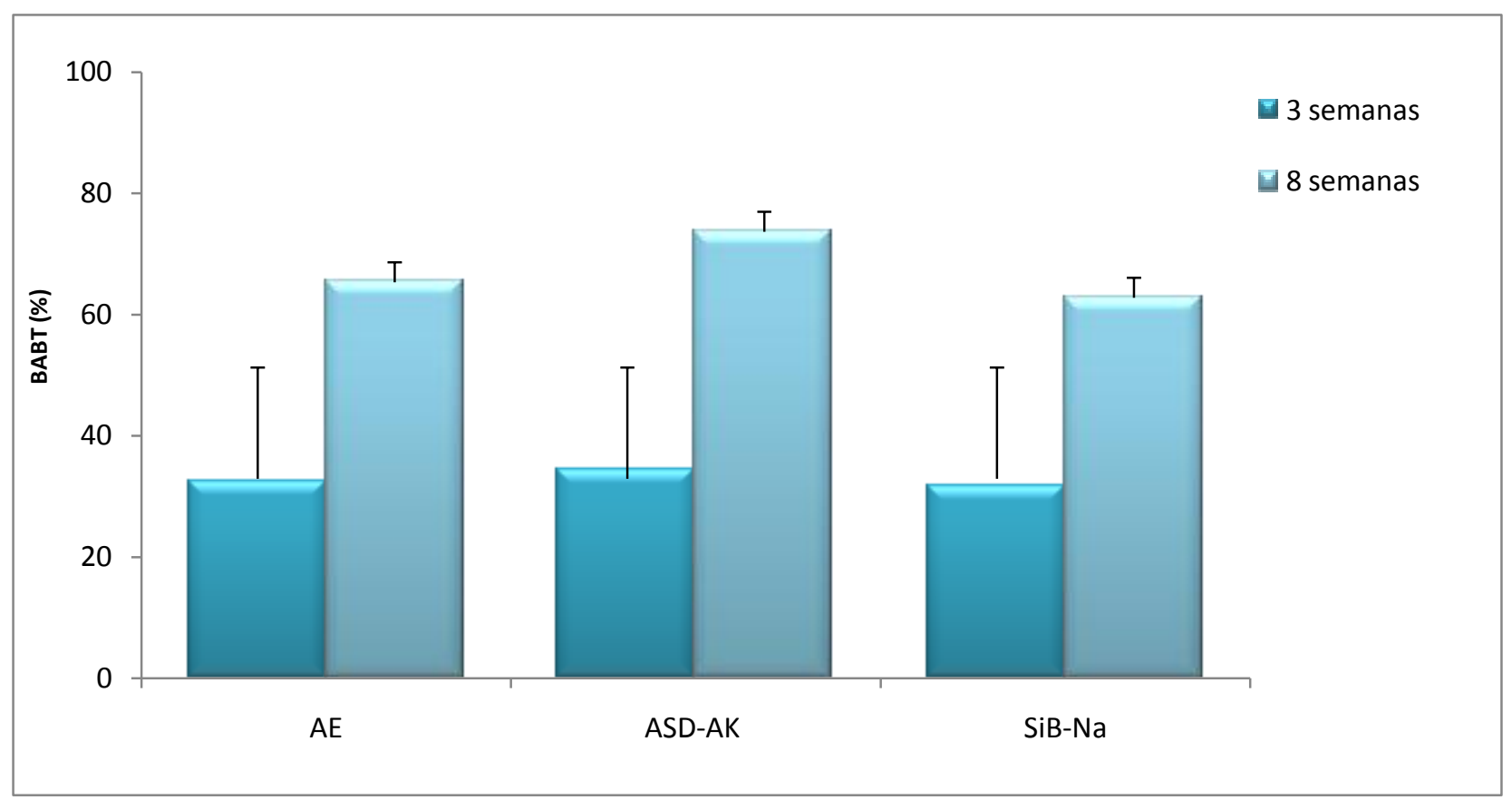

Figura 11. Formação óssea entre as roscas dos implantes (BABT) após 3 e 8 semanas de implantação para implantes com superfícies modificadas pelos tratamentos AE, ASD-AK e SiB-Na. Dados mostrados como média \pm desvio padrão (n=6). 


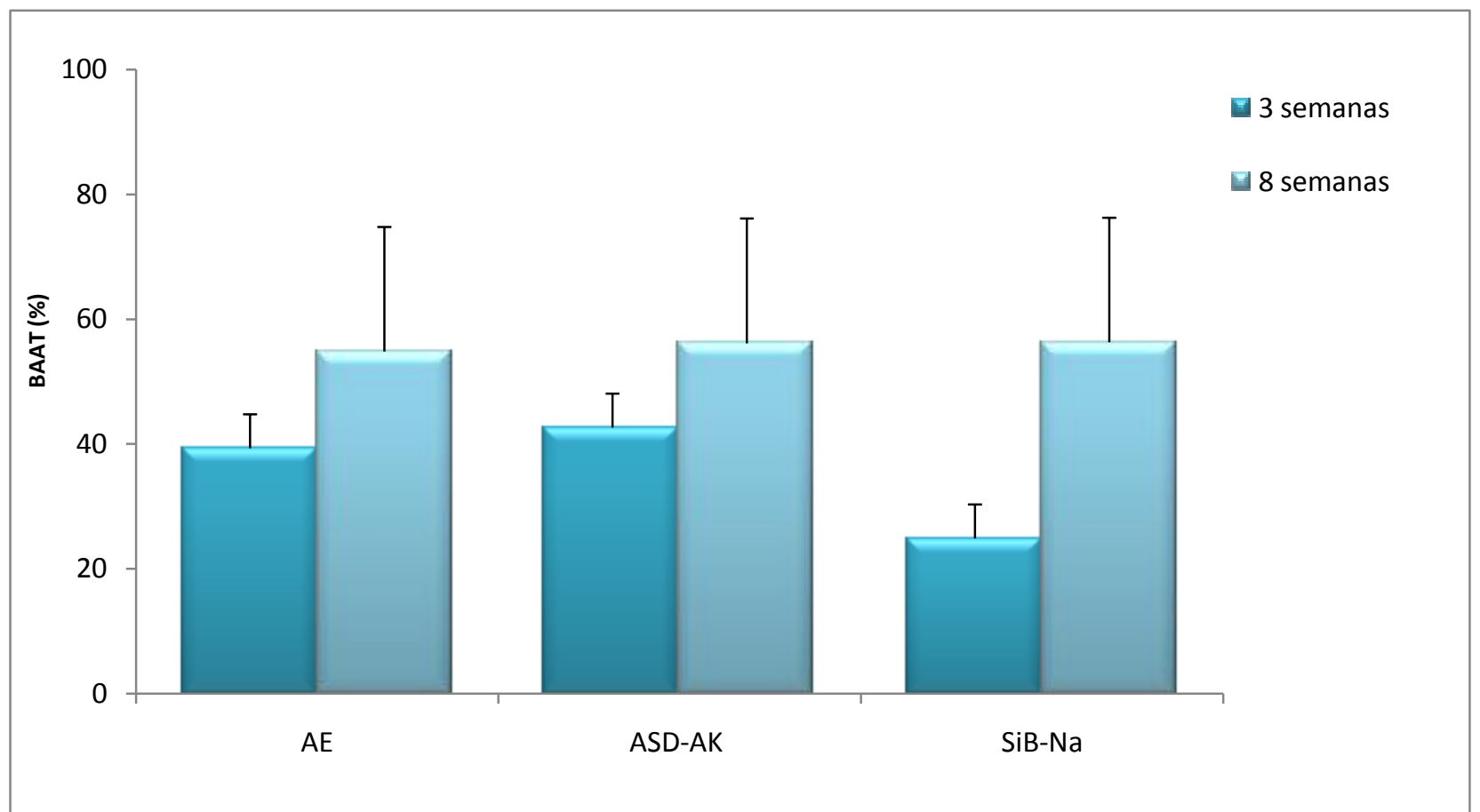

Figura 12. Formação óssea à distância da superfície dos implantes (BAAT) após 3 e 8 semanas de implantação para implantes com superfícies modificadas pelos tratamentos AE, ASD-AK e SiB-Na. Dados mostrados como média \pm desvio padrão (n=6). 


\section{DISCUSSÃO}

Os resultados desse estudo mostram que houve formação óssea em contato próximo com as superfícies de todos os implantes independentemente dos tratamentos realizados. Além disso, não foram observadas diferenças morfológicas ou morfométricas importantes que pudessem ser relacionadas aos tratamentos das superfícies dos implantes utilizados.

Após 3 semanas de implantação, o aspecto morfológico do tecido ósseo mostrava trabéculas revestidas por tecido osteóide com a presença de osteoblastos ativos, indicando a ocorrência de formação óssea. Tal aspecto raramente foi observado após 8 semanas de implantação. Interessante notar que, a formação óssea deve ser considerado o processo predominante nesse período de 3 semanas, mas que a remodelação continua a ocorrer, como comprovado pela presença de osteoclastos em algumas áreas próximas àquelas de formação óssea. Não foi observada qualquer diferença histológica na formação óssea entre as diferentes superfícies de implante avaliadas. Esses achados são corroborados por Ravanetti e cols. (2010) que, utilizando coelhos, também não observaram diferenças qualitativas na formação óssea entre implantes AE e ASD-AK.

A análise histomorfométrica mostrou que houve aumento na formação óssea de 3 para 8 semanas, como demonstrado pelo aumento nos valores de BIC, BABT e BAAT. Ao final de 8 semanas, os parâmetros avaliados apresentaram valores similares àqueles descritos em nossos artigos anteriores utilizando o mesmo modelo animal, mas implantes com tratamentos de superfície diferentes (Rosa e cols, 2006; Roriz e cols, 2010). Nesse modelo animal é possível considerar que o processo de osseointegração já esteja completo ao final de 8 semanas, uma vez que não ocorre aumento na formação até 12 semanas após a implantação (Rosa e cols., 2006). No entanto, não se pode 
descartar a possibilidade de ocorrer aumento, principalmente nos valores de BIC, uma vez que Albrektsson e Johansson (1991) demonstraram que áreas com reduzida porcentagem de contato osso-implante em períodos precoces podem alcançar níveis acima de $90 \%$ após um ano de observação.

Nesse estudo não foram observadas diferenças biologicamente importantes no contato osso implante, na formação óssea entre as roscas ou à distância dos implantes entres as três superfícies avaliadas. Esses resultados estão em acordo com os descritos por Ravanetti e cols. (2010) que também não encontraram diferenças no contato osso implante entre superfícies tratadas por ataque ácido e ASD-AK após 4 semanas de implantação em fêmures de coelhos. No entanto, maior contato osso-implante nas superfícies ASD-AK foi observado em períodos mais iniciais, sugerindo que esse tratamento poderia acelerar a formação óssea (Ravanetti e cols., 2010). Isso ocorreria porque superfícies modificadas por ASD-AK in vitro facilitam a adesão de osteoblastos, aumentam a atividade de fosfatase alcalina e a síntese de colágeno (Franco e cols., 2009; Ravanetti e cols., 2010), além de in vivo exibirem uma tendência a aumentar a osteogênese de contato (Franco e cols., 2008).

Superfícies de Ti modificadas pelo método $\mathrm{SiB}-\mathrm{Na}$ foram primeiro descritas por Della Valle e cols. (2009) como caracterizadas por serem altamente hidrofílicas e desenvolverem uma espessa camada de revestimento de hidroxiapatita ao serem tratadas com fluído corporal simulado. Do ponto de vista biológico, in vitro essas superfícies permitiram maior proliferação celular, maior expressão de osteocalcina por células osteoblásticas MG63 e maior formação de matriz mineralizada por osteoblastos derivados de osso alveolar humano (Della Valle e cols., 2009; Rosa e cols., 2009). Nesse estudo, os implantes modificados pelo método SiB-Na apresentaram o mesmo 
padrão de formação óssea e valores de BIC, BABT e BAAT não estatisticamente diferente dos tratamentos AE e ASD-AK.

Os resultados desse estudo mostram que os implantes modificados por duplo ataque ácido e anodização utilizando diferentes soluções permitem a formação óssea em contato próximo e nas adjacências dos mesmos de forma similar, quer seja em termos qualitativos como quantitativos. Portanto, esses tratamentos deveriam ser avaliados clinicamente na reabilitação implanto-suportada de pacientes parcial ou totalmente edêntulos. 


\section{CONCLUSÃO}

Diante dos resultados obtidos, podemos concluir que:

- Todos os tratamentos (AE, ASD-AK e SiB-Na) permitiram formação óssea in vivo em contato direto e adjacente à superfície dos implantes de Ti, sem apresentar diferenças qualitativas e quantitativas no padrão de reparo ósseo. 


\section{REFERÊNCIAS BIBLIOGRÁFICAS}

ALBREKTSSON, T.; JOHANSSON, J. Quantified bone tissue reactions to various metallic materials with reference to the so-called osseointegration concept. In: Davies JE. The Bone-Biomaterial Interface. Bufallo: University of Toronto Press, 1991. Cap.32, p. 357-363.

ALBREKTSSON, T.; WENNERBERG, A. Oral implant surfaces: Part 1 - review focusingon topographic and chemical properties of different surfaces and in vivo responses to them. Int J Prosthod, 2004. v.17, p.536-543.

BARROS, R.R.M.; NOVAES Jr., A. B.; PAPALEXIOU, V.; SOUZA, S. L. S.; TABA Jr., M.; PALIOTO, D. B.; GRISI, M. F. M. Effect of Biofunctionalized Implant Surface onOsseointegration - A Histomorphometric Study in Dogs. Braz Dent J. 2009, 20(2): 91-98.

BARROS, R.R.M.; NOVAES Jr., A. B.; MUGLIA, V. A.; IEZZI, G.; PIATTELLI, A. Influence of interimplant distances and placement depth on peri-implant bone remodeling of adjacent and immediately loadedMorse cone connection implants: a histomorphometric study in dogs. Clin. Oral Impl. Res. 2010, 21, 371-378.

COCHRAN, D.L. A comparison of endosseous dental implant surfaces. J Periodontol. 1999, 70(12): 1523-39.

DELlA VAllE, R.G.; VENUTI, E.; BRILlANTE, A.; GIRLANDO, A. Molecular dynamics simulations for a pentacene monolayer on amorphous silica. Chemphyschem. 2009, 3; 10(11):1783-8.

FERGUSON, S.J.; LANGHOFF, J.D.; VOELTER, K.; VON RECHENBERG, B.; SCHARNWEBER, D.; BIERBAUM, S.; SCHNABELRAUCH, M.; KAUTZ, A.R.; FRAUCHIGER, V.M.; MUELLER, T.L.; VAN LENTHE, G.H.; SCHLOTTIG, F. Biomechanical Comparison of different surface modification for dental implants. Int $\mathbf{J}$ Oral Maxillofac Implants. 2008, 23(6):1037-46.

FILIAGGI, M.J.; COOMBS, N.A.; PILLIAR, R.M. Characterization of the interface in plasma-sprayed HA coating/Ti-6Al-4V implant system. J Biomed Mater Res. 1991, v.25, p.1211-1229.

FINI, M.; CIGADA, A.; RONDELLI, G.; CHIESA, R.; GIARDINO, R.; GIAVARESI, G.; ALDININ, N.; TORRICELLI, P.; VICENTINI, B. In vitro and in vivo behaviour of Ca- and Penriched anodized titanium. Biomaterials. 1999.v.20, p.1587-1594. 
FRANCO, R.L. Biocompatibilidade de titânio com superfície quimicamente modificada pela deposição de $\mathrm{Ca}$ e $\mathrm{P}$. Estudo in vitro e in vivo. Dissertação de mestrado. Universidade de São Paulo, 2006.

FRANCO, R.L.; CHIESA, R.; BELOTI,M.M.; OLIVEIRA, P. T.; ROSA, A. Bone Response to a Ca- and P-Enriched Titanium Surface Obtained by Anodization. Braz Dent J. 2008, 19(1): 15-20.

FRANCO, R.L.; CHIESA, R.; BELOTI,M.M.; OLIVEIRA, P. T.; ROSA, A. L. Human osteoblastic cell response to a $\mathrm{Ca}$ - and $\mathrm{P}$-enriched titanium surface obtained by anodization. J Biomed Mater Res. 2009, 88A: 841-848.

ISHIZAWA, H.; OGINO, M. formation and characterization of anodic titanium oxide films containing Ca and P. J Biomed Mater Res, 1995.v.29, p.65-72.

JARCHO, M. Calcium phosphate ceramics as hard tissue prosthetics. Clin Orthop. 1981, v.157, p.259-278.

KIESWETTER, K.; SCHWARTZ, Z.; HUMMERT T.W.; COCHRAN, D.L.; SIMPSON, J.; DEAN, D.D.; BOYAN B.D. Surface roughness modulates the local production of growth factors and cytokines by osteoblast-like MG-63 cells. J Biomed Mater Res, 1996.v.32, p.55-63.

KIM, K.H.; RAMASWAMY, N. Electrochemical surface modification of titanium in dentistry. Dent Mater J. 2009 Jan;28 (1):20-36.

KOKUBO, T.; KIM, H-M.; MIYAJI, F.; NAKAMURA, T. Preparation of bioactive Ti and its alloys via simple chemical surface treatment. J Biomed Mater Res, 1996.v.32, p.409-417.

KRYSSMAN, W.; KURZE, P.; DITTRICH, K-H.; SCHNEIDER, H-G. Process characteristics and parameters of anodic oxidation by spark deposition (ANOF). Crystal Res Technol, 1984.v.19, p.973-979.

KURZE, P. Method for producing oxide ceramic layers on barrier layer-forming metals and articles produced by the method. U.S. Patent No. 6495267, 1995.

MANIATOPOULOS, C.; RODRIGUEZ, A.; DEPORTER, D.A.; MELCHER, A.H. An improved method for preparing histological sections of metallic implants. Int J Oral Maxillofac Implants. 1986, v.1, p.31-37.

MARTIN, J.Y.; SCHWARTZ, Z.; HUMMERT, T.W.; SCHRAUB, D.M.; SIMPSON, J.; LANKFORD, J.; DEAN, D.D.; COCHRAN, D.L.; BOYAN, B.D. Effect of titanium surface roughness on proliferation, differentiation and protein synthesis of human 
osteoblast-like cells (MG63). J Biomed Mater Res, 1995. v.29, p.389-401.

MORRA, M.; CASSINELli, C.; CASCARDO, G.; CAHALAN, P.; CAHALAN, L.; FINI, M.; GIARDINO, R. Surface engineering of titanium by collagen immobilization. Surface characterization and in vitro and in vivo studies. Biomaterials. 2003, v.24, p.4639-4654.

PULEO, D.A.; NANCI, A. Understanding and controlling the bone implant interface.

Biomaterials, 1999.v.20, p.2311-2321.

RAVANETTI, F.; BORGHETTI, P.; DE ANGELIS, E.; CHIESA, R.; MARTINI, F.M.; GABBI, C.; CACCHIOLI, A. In vitro cellular response and in vivo primary osteointegration of electrochemically modified titanium. Acta Biomater. 2010 Mar; 6(3):1014-24.

RORIZ, V.M.; ROSA, A.L.; PEITL, O.; ZANOTTO, E.D.; PANZERI, H.; DE OLIVEIRA, P.T. Efficacy of a bioactive glass-ceramic (Biosilicate) in the maintenance of alveolar ridges and in osseointegration of titanium implants. Clin Oral Implants Res. 2010 Feb; 21(2):148-55.

ROSA, A.L.; OLIVEIRA, C.S.R.; BELOTI, M.M.; DE OLIVEIRA, P.T. Effect of microcapsules containing TAK-778 on bone formation around osseointegrated implants: Histomorphometric analysis in dogs. Implant Dent, 2006, v. 15, p. 97-103.

ROSA, A.L.; BELOTI, M.M. Rat bone marrow cell response to titanium and titanium alloy with different surface roughness. Clin Oral Implants Res. 2003a. v.14, p.43-48.

ROSA, A.L.; BELOTI, M.M. Effect of cpTi surface roughness on human bone marrow cell attachment, proliferation, and differentiation. Braz Dent J, 2003b. v.14, p.16-21,

ROSA, A.L., DE OLIVEIRA, C.S., BELOTI, M.M., XAVIER, S.P.; DE OLIVEIRA, P.T. Effect of microcapsules containing TAK-778 on bone formation around osseointegrated implants: histomorphometric analysis in dogs. Implant Dent, 2006. v. 15, p. 97-103.

ROSA, A.L.; SHAREEF, M.Y.; VAN NOORT, R. Efeito das condições de preparação e sinterização sobre a porosidade da hidroxiapatita. Pesqui Odontol Bras, 2000. v.14, p.273-277.

SANDRINI, E.; CHIESA, R.; RONDELLI, M.; SANTIN, M.; CIGADA, A. A novel biomimetic treatment for an improved osteointegration of titanium. J Appl Biomat Biomech, 2003. v.1, p.33-42. 
SANDRINI, E.; MORRIS, C.; CHIESA, R.; CIGADA, A.; SANTIN, M. In Vitro Assessment of the Osteointegrative Potential of a Novel Multiphase Anodic Spark Deposition Coating for Orthopaedic and Dental Implants. J Biomed Mater Res Part B: Appl Biomater. 2005, 73B: 392-399.

SATSANGI, A.; SATSANGI, N.; GLOVER, R.; SATSANGI, R.K.; ONG, J.L. Osteoblast response to phospholipid modified titanium surface. Biomaterials, 2003. v.24, p.4585-4589.

SCHWARTZ, Z.; KIESWETTER, K.; DEAN, D.D.; BOYAN, B.D. Underlying mechanisms at the bone surface interface during regeneration. J Periodontal Res, 1997. v.32, p.166-171.

STADLINGER, B.; BIERBAUM, S.; GRIMMER, S.; SCHULZ, M.C.; KUHLISCH, E.; SCHARNWEBER, D.; ECKELT, U.; MAI, R. Increased bone formation around coated implants. J Clin Periodontol. 2009 Aug; 36(8):698-704.

STADLINGER, B.; LODE, A.T.; ECKEL, T. U.; RANGE, U.; SCHLOTTIG, F.; HEFTI, T.; MAI, R. Surface-conditioned dental implants: an animal study on bone formation. J Clin Periodontol. 2009 Oct; 36(10):882-91.

TAVARES, M.G; OLIVEIRA, P.T.; NANCI, A.; HAWTHORNE, A.; ROSA, A.L.; XAVIER, X.P. Treatment of a commercial, machined surface titanium implant with H2SO4/H2O2 enhances contact osteogenesis. Clin Oral Implants Res, 2007. v.18, p.452-458.

TISEL, C.L.; GOLDBERG, V.M.; PARR, J.A.; BENSUSAN, J.S.; STIKOFF, L.S.;

STEVENSON, S. The influence of a hydroxyapatite and tricalcium-phosphate coating on bone growth into titanium fiber-metal implants. J Bone Joint Surg A, 1994. v.76, p.139-171.

WALL, I.; DONOS, N.; CARLQVIST, K.; JONES, F.; BRETT, P. Modified titanium surfaces promote accelerated osteogenic differentiation of mesenchymal stromal cells in vitro. Bone. 2009 Jul;45(1):17-26.

WENNERBERG, A.; HALLGREN, C.; JOHANSSON, C.; DANELlI, S. A histomorphometric evaluation of screw-shaped implants each prepared with two surface roughnesses. Clin Oral Implants Res, 1998. v.99, p.11-19.

XAVIER, P.; CARVALHO, P.S.P.; BELOTI, M.M.; ROSA, A.L. Response of rat bone marrow cells to commercially pure titanium submitted to different surface treatments. $\mathbf{J}$ Dent, 2003. v.31, p.173-180. 
ZHU, X.; KIM, K-H.; JEONG, Y. Anodic oxide films containing Ca and P of titanium. Biomaterials, 2001. v.22, p.2199-2206. 